\title{
Right postpneumonectomy syndrome and severe pectus excavatum in a child: Surgical management
}

\author{
Victor 0. Morell, MD, Jeffrey P. Jacobs, MD, ${ }^{b}$ and James A. Quintessenza, MD, \\ Tampa and St Petersburg, Fla
}

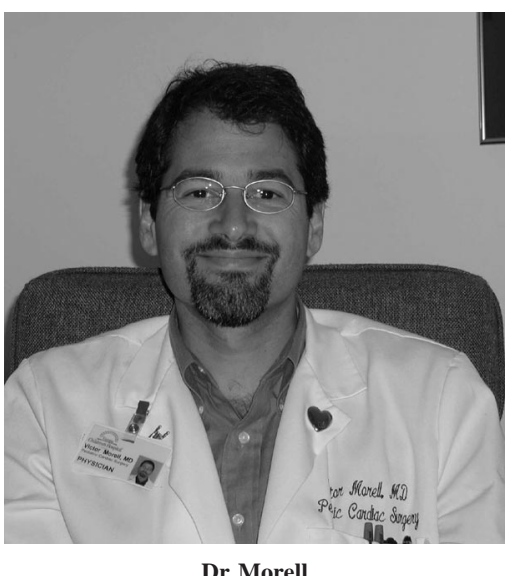

$\mathrm{P}$ ostpneumonectomy syndrome is an uncommon complication seen after a right pneumonectomy. In this condition there is shifting of the mediastinal contents into the vacant right pleural cavity. This results in tracheal or left main stem bronchial compression between the aorta or spine posteriorly and the left pulmonary artery anteriorly. ${ }^{1-5}$ Malacic changes eventually develop in the affected tracheobronchial segment. ${ }^{1,3}$ Airway compression causes respiratory symptoms, consisting of stridor, progressive dyspnea, and recurrent respiratory tract infections, in affected patients. ${ }^{1-5}$ Once symptoms are present, aggressive management is indicated to protect the remaining lung. We describe the surgical treatment of a 6-year-old child with postpneumonectomy syndrome complicated by severe pectus excavatum.

\section{Clinical Summary}

The patient is a 6-year-old girl who as a neonate underwent a right pneumonectomy for congenital arteriovenous malformations involving the right lung. Since early childhood, she had recurrent respiratory tract infections requiring multiple hospitalizations. By the time she was 2 years old, there was significant mediastinal shifting to the right, prompting the placement of a tissue expander in the right pleural space to help correct the mediastinal shift.

In October 1997 the patient was readmitted to the hospital with a respiratory tract infection. Bronchoscopy revealed the presence of severe compression of the proximal left main stem bronchus. A chest computed tomographic scan revealed a severe right mediastinal shift in which the heart was located in the right costophrenic

From the Department of Pediatric Cardiovascular Surgery, Tampa Children's Hospital, Tampa, ${ }^{\text {a }}$ and the Division of Thoracic and Cardiovascular Surgery, All Children's Hospital, St Petersburg, ${ }^{\text {b }}$ Fla.

Received for publication Dec 26, 2001; accepted for publication Jan 11, 2002

Address for reprints: Victor O. Morell, MD, Chief of Pediatric Cardiac Surgery, Tampa Children's Hospital, 3005 W M.L.K. Blvd, Suite 102, Tampa, FL 33607 (E-mail: vmorell@ heartsurgery-csa.com).

J Thorac Cardiovasc Surg 2002;124:203-4

Copyright (C) 2002 by The American Association for Thoracic Surgery

$0022-5223 / 2002 \$ 35.00+0 \quad \mathbf{1 2 / 5 4 / 1 2 2 8 9 4}$

doi:10.1067/mtc.2002.122894 angle, the tissue expander was superior to the heart, the left main stem bronchus was compressed between the aorta and the left pulmonary artery, and a severe sternal depression was noted (Figure 1).

Surgical correction of the postpneumonectomy syndrome and pectus excavatum was undertaken through a sternotomy with a transverse submammary incision. First, the abnormal costochondral cartilages were removed in a subperichondrial fashion, and the sternum was disarticulated at the sternomanubrial junction. The displaced heart and aorta were then carefully dissected and mobilized to their normal anatomic positions. The old tissue expander was replaced with a larger one. Multiple nonabsorbable sutures were placed from the right edge of the pericardium to the anterior chest wall to prevent cardiac shifting. The body of the sternum was remodeled and reattached to the manubrium. Two stainless steel plates were placed across the anterior chest wall underneath the sternum to provide stability and protection of the reconstructed chest wall. The incision was then closed and drained in a standard fashion.

The patient had an uneventful recovery, and bronchoscopy at the time of discharge revealed no evidence of bronchial compression. Six months after the procedure, the chest wall stainless steel plates were removed. Since the operation 4 years ago, the patient has remained completely free of symptoms. On her latest chest computed tomographic scan, there were no signs of mediastinal shift or bronchial compression (Figure 2).

\section{Discussion}

Postpneumonectomy syndrome is most frequently reported in children. The incidence has been estimated to be 1 case per 640 pneumonectomies. ${ }^{1}$ Most cases occur after a right pneumonectomy, but the syndrome is occasionally seen after a left pneumonectomy in patients with a right aortic arch and mediastinal anomalies. 2,5

The management of postpneumonectomy syndrome is directed toward relieving tracheobronchial compression. There is recent interest in the use of endobronchial stents in adults, because there is no concern about growth potential. ${ }^{2}$ For pediatric patients, surgery remains the preferred treatment option.

Numerous surgical procedures have been described for the management of postpneumonectomy syndrome, including the placement of an interposition graft between the ascending and 


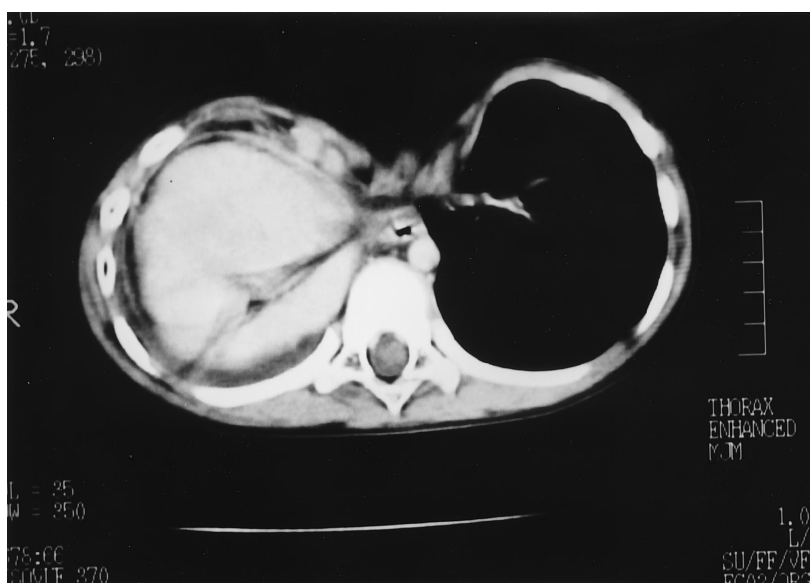

Figure 1. Preoperative computed tomographic scan of chest, demonstrating cardiac shift into right pleural space and severe sternal depression.

descending aorta, placement of saline and albumin solution into the empty pleural space, right phrenectomy, and mediastinal repositioning with placement of an expandable prosthesis in the empty pleural space to prevent mediastinal shifting. ${ }^{1,3,4,5}$ The last procedure is our preferred method of treatment and was therefore used in this case.

Our patient represents the first reported case in which this syndrome was associated with a pectus excavatum deformity. The presence of significant sternal depression limited the ability to perform a mediastinal repositioning procedure through a thoracotomy approach, as described by Grillo and colleagues. ${ }^{4}$ We therefore used a sternotomy approach, which allowed us to repair the pectus excavatum, mobilize the mediastinal structures, perform the cardiopexy, and replace the right pleural expandable prosthesis with ease.

Since this initial case, we have used the sternotomy approach in the management of a child born with right lung agenesis in whom a postpneumonectomy syndrome developed, with similar results. We believe that the sternotomy approach permits better mobiliza-

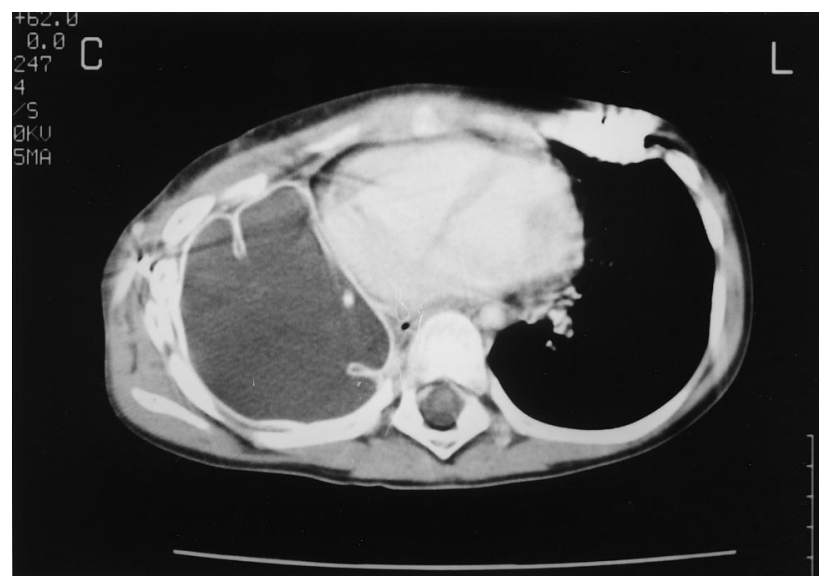

Figure 2. Postoperative computed tomographic scan of chest, demonstrating midline cardiac structures with tissue expander filling right pleural space and normal chest wall geometry.

tion of the mediastinal contents back to more normal anatomic position and results in better long-term outcome for patients with postpneumonectomy syndrome, with or without chest wall deformities.

\section{References}

1. Jensen JP, Brutel de la Riviere A, Alting MP, Westermann CJ, Bergstein PG, Duurkens VA. Pneumonectomy syndrome in adulthood: surgical correction using an expandable prosthesis. Chest. 1992; 101:1167-70.

2. Cordova FC, Travaline JM, O’Brien GM, Ball DS, Lippmann M. Treatment of left pneumonectomy syndrome with an expandable endobronchial prosthesis. Chest. 1996;109:567-70.

3. Riveron FA, Adams C, Lewis JW, Ochs D, Glines C, Popovich J. Silastic prosthesis plombage for right postpneumonectomy syndrome. Ann Thorac Surg. 1990;50:465-6.

4. Grillo HC, Shepard JO, Mathisen DJ, Kanarek DJ. Postpneumonectomy syndrome: diagnosis, management, and results. Ann Thorac Surg. 1992;54:638-51.

5. Quillen SP, Schackelford GD. Postpneumonectomy syndrome after left lung resection. Radiology. 1991;179:100-2. 